\title{
Pitfalls to Avoid During Development of Anti-SARS-COV-2 Vaccine
}

\author{
Rashika Ahmed El Ridi ${ }^{1}$, Hatem Tallima ${ }^{2,3}$, and Rashika El Ridi ${ }^{2}$ \\ ${ }^{1}$ Affiliation not available \\ ${ }^{2}$ Zoology Department, Faculty of Science, Cairo University \\ ${ }^{3}$ Department of Chemistry, School of Science and Engineering, American University
}

December 3, 2020

\section{Hosted file}

Pre-Print Pitfalls to Avoid.pdf available at https://authorea.com/users/381061/articles/ 496864-pitfalls-to-avoid-during-development-of-anti-sars-cov-2-vaccine 